\title{
Destek Vektör Makineleri ile MODIS Verisinden Fraksiyonel Kar Örtüsünün Ilgaz Orman İşletme Müdürlüğü Bölgesinde Belirlenmesi
}

\author{
Bora Berkay ÇifTÇi ${ }^{1}$, Semih KUTER ${ }^{2 *}$ \\ ${ }^{1}$ Kırşehir Gençlik ve Spor İl Müdürlüğü, Kaman Yurt Müdürlüğü, 40300, KIRŞEHİR \\ 2* Çankırı Karatekin Üniversitesi, Orman Fakültesi, Orman Mühendisliği Bölümü,18200, ÇANKIRI
}

Öz

Bu çalışmada, Çankırı ve Kastamonu il sınırları içinde yer alan Ilgaz Orman İşletme Müdürlüğü bölgesinde, orta çözünürlüklü görüntüleme spektroradyometresi (MODIS) verisinden etkili kar kaplı alan (EKKA) haritalaması amacıyla destek vektör makineleri (DVM) tasarımı araştırılmıştır. DVM modellerin eğitilmesinde, Mart 2000 ve Nisan 2016 tarihleri arasında alınan MODIS görüntülerinden elde edilen toplam 10 bağımsız değişken; MODIS bant 1-7 atmosfer üstü reflektans değerleri, normalize fark kar indisi, normalize fark vejetasyon indisi ve arazi sınıfı kullanılmıştır. Referans EKKA haritaları daha yüksek mekânsal çözünürlüğe sahip ilgili Landsat 7/8 görüntülerinden üretilmiştir. DVM modellerinin doğruluğu, eğitim verilerinin boyutuna ve örneklem türüne göre değerlendirilmiş̧tir. Kernel türünün DVM modellerinin doğruluğu üzerindeki etkisi de incelenmiştir. Sonuçlara göre, doğrusal, 2., 3. ve 4. dereceden polinomların yanı sıra radyal temel fonksiyonu (RBF) kernelleri ile eğitilmiş tüm DVM modelleri, ilgili referans EKKA haritaları ile yüksek korelasyon oranları vermektedir $(R \geq$ 0,91 ). Öte yandan, MODIS'in standart EKKA ürünü olan MOD10A1, ortalama $R=0,77$ ile biraz daha zayıf performans sergilemektedir. Eğitim aşamasında harcanan CPU zamanlarına göre hesaplama etkinliği bakımından, RBF kernelinin, küçük, orta ve büyük boyutlu eğitim veri setleri için sırasıyla 279, 2300 ve 8457 saniyelik ortalama model oluşturma süreleriyle daha üstün olduğu görülmüştür.

Anahtar Kelimeler: Karın uzaktan algılanması, MODIS, Landsat, destek vektör regresyonu.

\section{Estimation of Fractional Snow Cover from MODIS Data in Ilgaz Forest District Region by Support Vector Machines}

\begin{abstract}
This study is focused on the assessment of support vector machines (SVM) in order to estimate the fractional snow cover (FSC) from coarse spatial resolution moderate resolution imaging spectroradiometer (MODIS) imagery in Ilgaz Forest District area located within the cities of Çankırı and Kastamonu. SVM model training is carried out by employing 10 predictor variables obtained from MODIS images taken between March 2000 and April 2016, namely, MODIS top-of-atmospheric reflectance values of bands 1-7, normalized difference snow index, normalized difference vegetation index and land cover class. Higher resolution Landsat 7/8 images are used to generate the corresponding reference FSC maps. Accuracy of SVM models are assessed with respect to the size of the training data and the sampling type. The impact of the kernel type on the accuracy of the SVM models is also investigated. According to the results, all SVM models trained with linear, $2^{\text {nd }}, 3^{\text {rd }}$ and $4^{\text {th }}$ order polynomials as well as radial basis function (RBF) kernels give high correlation rates with the associated reference FSC maps $(R \geq 0,91)$. On the other hand, MOD10A1, the standard FSC product of MODIS, exhibits slightly poorer performance with average $R=0,77$. In terms of computational efficiency with respect to CPU times spent during the training stage, RBF kernel is found to be superior with average model building times of 279,2300 and 8457 seconds for small-, medium- and large-sized training data sets, respectively.
\end{abstract}

Keywords: Remote sensing of snow, MODIS, Landsat, support vector regression.

\footnotetext{
*Sorumlu Yazar (Corresponding Author):

Semih KUTER (Dr.); Çankırı Karatekin Üniversitesi, Orman Fakültesi, Orman

Mühendisliği Bölümü, 18200, Çankırı-Türkiye. Tel: +90 (376) 2122757 ,

Fax: +90 (376) 213 6983, E-mail: semihkuter@ karatekin.edu.tr

ORCID: 0000-0002-4760-3816 


\section{Giriş}

Kar, dünya yüzeyinin önemli bir fiziki öğesi olup, mekânsal ve zamansal dağılımının sürekli gözlemlenmesi temel çevre araştırmaları açısından oldukça önemlidir. İklim bilimi açısından bakıldığında kar örtüsü, (i) elektromanyetik spektrumun görünür ve kızılötesine yakın bölgelerindeki yüksek albedosu sayesinde güneşten gelen 1şı̆̆ın büyük miktarını yansıttığı (Dietz vd., 2012), ve (ii) zayıf 1sı iletkenliği özelliğiyle bir yalıtkan madde gibi davranarak kış boyunca dünya yüzeyinden ısının serbest bırakılmasını engellediği için dünya ile atmosfer arasındaki enerji alışverişi süreci üzerinde doğrudan etkiye sahiptir (Zhang, 2005). Kar aynı zamanda orta ve yüksek enlemlerdeki Alpin kuşağının yanı sıra dünyanın dağlık bölgelerinin hidrolojisinde de önemli bir rol oynamaktadır (Lehning vd., 2006). Kar kütlesinde biriken su, kış mevsimi boyunca potansiyel bir sel baskını riski taşıyan yüksek miktarda donmuş su rezervi olarak işlev görmekte olup, aynı zamanda enerji ve su tedariki açısından kıymetli bir kaynak teşkil etmektedir (Akyürek vd., 2010; Romanov vd., 2003).

Güvenilir kar kaplı alan (KKA) tahminlemesi için metodolojiler geliştirilmesi uzun süredir uzaktan algılama (UA)'nın ilgi alanında yer almaktadır (Luojus vd., 2007; Siljamo ve Hyvärinen, 2011). EKKA haritalaması günümüzde hem bölgesel hem de küresel ölçekte yapılmakta olup UA ile günlük olarak üretilen kar ürünleri bulunmaktadır (Frei vd., 2012; Piazzi vd., 2019). Yüksek zamansal çözünürlüğü ve farklı mekansal çözünürlüklere sahip $0.4 \mu \mathrm{m}$ - $14.4 \mu \mathrm{m}$ dalga boyu aralığındaki 36 spektral bandı ile (bant 1-2: 250m, bant 3-7: 500m, ve bant 8-36: 1000m) Orta Çözünürlüklü Görüntüleme Spektroradyometresi (Moderate Resolution Imaging Spectroradiometer - MODIS), hem bölgesel hem de küresel ölçekte kar örtüsü haritalaması amacıyla en fazla kullanılan araçtır (Hall vd., 2002).

Kar örtüsü haritalama teknikleri: (i) ikili (binary) ve (ii) piksel altı (sub-pixel) sınıflandırma olmak üzere iki ana kategoride gruplandırılabilir. Geleneksel ikili yaklaşımda her bir piksel kar/kar değil olarak belirtilmektedir. Hall vd. (1995) tarafından geliştirilen ilk MODIS ikili kar örtüsü algoritması, elektromanyetik spektrumun görünür bölgelerinde $(0.4-0.7 \mu \mathrm{m})$ karın yüksek reflektans özelliği ile kısa ve orta kızıl ötesi bölgelerindeki düşük reflektans özelliğini (1 - $4 \mu \mathrm{m})$ kullanan normalize fark kar indisi (normalized difference snow index NDSI)'nin üzerine kuruludur. MODIS bant $4(0.545-0.565 \mu \mathrm{m})$ ve bant $6(1.628-1.652 \mu \mathrm{m})$ NDSI'yi hesaplamada kullanılmaktadır:

$$
\mathrm{NDSI}_{M O D I S}=\frac{\text { bant } 4-\text { bant } 6}{\text { bant } 4+\text { bant } 6}
$$

$\mathrm{Bu}$ orantı karı bulutlardan ve aynı zamanda karla kaplı olmayan yüzeylerden ayırt etmeye yaramaktadır. Algoritmanın ilk sürümünde orman bakımından yoğun olmayan bir alanda kar haritalaması için gereken koşullara göre; NDSI $\geq 0.4$, bant 2 reflektan değeri $>\% 11$ (karın sudan ayrılması için) ve bant 4 reflektans değeri $\geq \% 10$ (yüksek NDSI değerlerine rağmen karanlık hedeflerin yanlışlıkla kar olarak sınıflandırılmasını önlemek için) olmalıdır (Klein ve Barnett, 2003). Bununla birlikte, ikili formattaki KKA verileri, iklim, hidrolojik ve sayısal hava modellerinde belirsizlikleri artırabilmektedir, çünkü KKA'nın fraksiyonel özelliğinden yoksun olması, özellikle karın birikimi ve erime süresi boyunca KKA'nın mevsimsel dinamiklerini doğru bir şekilde tahmin edebilmeyi engellemektedir (Dietz vd., 2012; Romanov vd., 2003). Sonuç olarak dağılımlı fiziki modellerdeki kar karakteristiklerini kullanmak için piksel altı sınıflandırma yaklaşımı kullanılarak EKKA haritaları üretilmek zorundadır (Dietz vd., 2012).

Veri madenciliği ve istatistiksel öğrenme teorilerine dayanan destek vektör makineleri (support vector machines - DVM) (Vapnik, 1995) gelişmiş bir denetimli parametrik olmayan sınıflandırma ve regresyon aracıdır. Sismoloji (Fisher vd., 2017), finans (Kumar vd., 2016), yüz tanıma (Liu ve Chen, 2007), yazı sinıflandırma (Shanthi ve Duraiswamy, 2010), biyobilişim (Kumar ve Shelokar, 2008) ve UA (Melgani ve Bruzzone, 2004) gibi farklı bilimsel disiplinlerdeki birçok uygulamada başarılı bir şekilde kullanılmaktadır. DVM'lerin arkasındaki temel mantık, sınıfların optimal ayrımını veren karar sınırlarının yerinin belirlenmesidir (Vapnik, 1995). DVM'ler ilk olarak örüntü tanımlama görevleri için geliştirilmiş olsalar da regresyon ve zaman serilerinin tahminlenmesine yönelik uygulamalarda da başarılı sonuçlar vermişlerdir (Mattera ve Haykin, 1999; Müller vd., 1997). DVM'ler görüntü sınıflandırma ve UA'daki regresyon (Bruzzone ve Melgani, 2005; Kaheil vd., 2008; Zheng vd., 2008) görevlerinde başarılı şekilde uygulanmışlardır, ancak henüz EKKA tahminlenmesine yönelik olarak DVM'lerin kullanımıyla ilgili detaylı herhangi bir çalışma bulunmamaktadır.

Bilindiği üzere tüm parametrik olmayan sınıflandırma ve regresyon yöntemlerinde olduğu gibi, DVM'ler de modelin daha önce görmediği veriyi genelleme yeteneğini doğrudan etkileyen "model ayarlama" parametrelerine sahiptirler. Dolayısıyla bu çalışmanın birincil temel amacı UA'da EKKA haritalaması amacıyla DVM tasarımının detaylı olarak araştırılarak, en uygun DVM model ayarlama parametrelerinin seçilen çalışma 
sahası örneğinde ortaya konulmasıdır. Çalışmanın ikincil temel amacı ise, DVM modellerin eğitimi sırasında kullanılan eğitim veri setinin oluşturulmasında seçilen örneklem tipinin ve örneklem boyutunun nihai DVM modellerinin genelleme ve tahminleme becerisi üzerinde istatistiksel açıdan anlamlı bir etkisi olup olmadığının araştırılmasıdır. Eğitim veri setinin boyutu ile örneklem türünün ve ayrıca DVM kernel fonksiyonunun DVM modellerinin performansı üzerindeki etkileri araştırılarak, elde edilen sonuçlar sunulmuştur. Çalışmanın kalan kısmı şu şekilde düzenlenmiştir: 2. Bölümde, çalışmada kullanılan materyal ve yöntem verilmiştir. Çalışma sonucunda elde edilen bulgular ve sonuçlarla ilgili tartışma 3. Bölümde sunulmaktadır. Son olarak, 4. Bölümde çalışmada elde edilen genel bulgular ve sonuçlar kısaca özetlenerek, gelecekteki potansiyel çalışma konuları ile ilgili özet bilgiler aktarılmıştır.

\section{Materyal ve Metot}

\section{1. Çalışma Alanı}

Çalışma alanı olarak seçilen ve Türkiye'nin Çankırı ve Kastamonu illerinin sınırları içinde bulunan Ilgaz Orman İşletme Müdürlüğü 1960 yılında kurulmuş olup, yaklaşık $7520 \mathrm{~km}^{2}{ }^{2}$ lik bir alanı kapsamaktadır (Şekil 1). Ilgaz Orman İşletme Müdürlüğü orta Karadeniz bölümünün iç kısmında yer almaktadır. Doğudan Kastamonu Tosya, kuzeyden Kastamonu, batıdan Bolu Devrez, güneyden Çankırı İşletme Müdürlükleri ile komşudur.
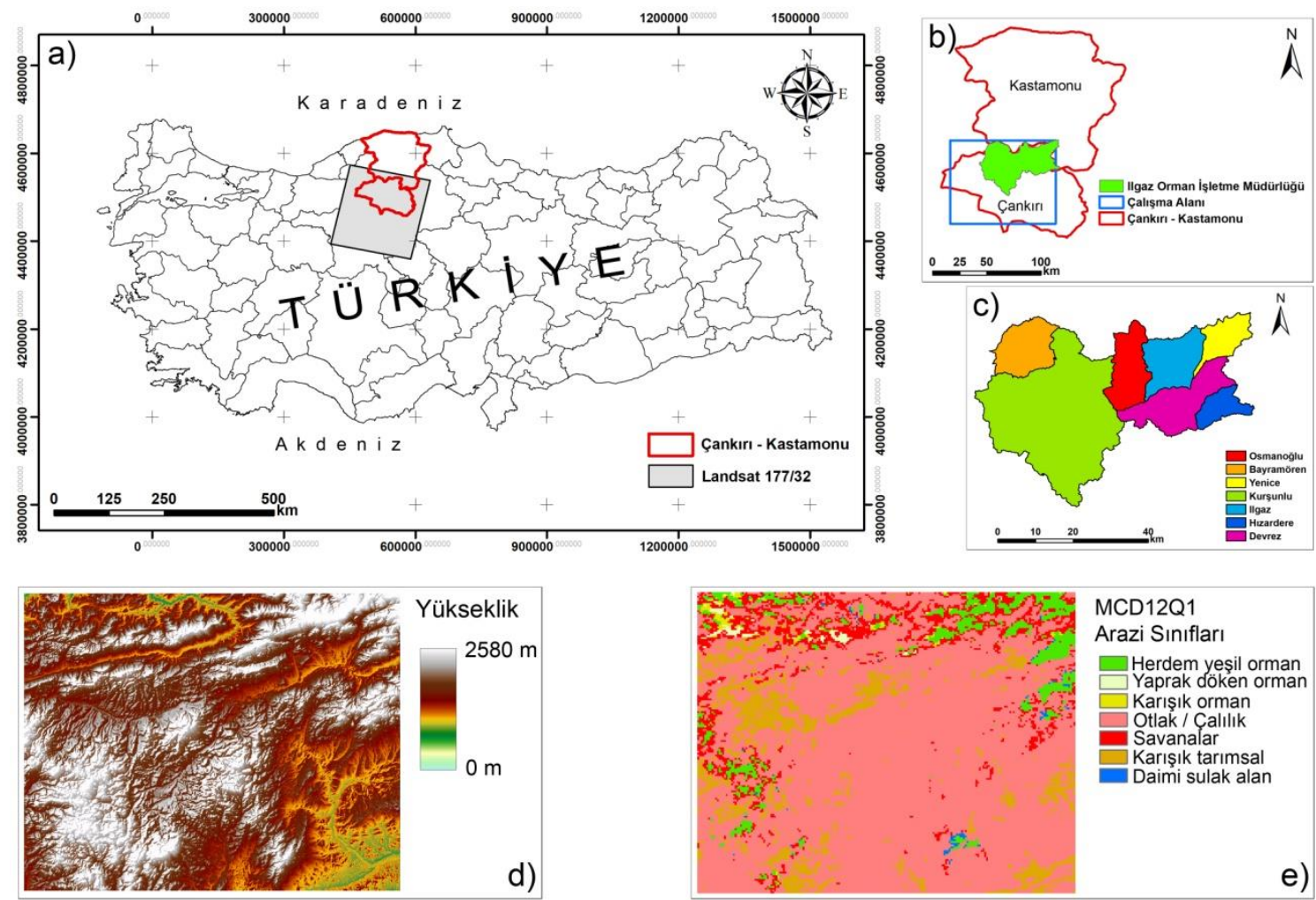

Şekil 1. a) Çankırı - Kastamonu il sınırları ve Landsat 177/32 karosunun konumu, b) Ilgaz Orman İşletme Müdürlüğü sınırı ve çalışma alanı, c) Ilgaz Orman İşletme Müdürlüğüne bağlı işletme şeflik sınırları, d) çalışma alanı sayısal yükseklik haritası, e) çalışma alanı MODIS MCD12Q1 arazi sınıfları.

Ilgaz Orman İşletme Müdürlüğü sınırlarındaki ormanlar, genel olarak Karadeniz ve karasal iklim kuşağ1 arasında kalmaktadır (Kuter, 2008). Çalışma alanının rakımı ortalama deniz seviyesinden 510-2540m arasında değişen yüksekliktedir. Bitki örtüsü temel olarak orman, çalılık ve alp bitkilerinden müteşekkildir. Kuzey yamaçların düşük rakımlı yerleri genellikle meşe (Quercus spp.), karaçam (Pinus nigra ssp. pallasiana), Uludağ köknarı (Abies nordmanniana spp. bornmulleriana) ormanlarıyla kaplıdırlar. 1000-1300m rakımlarda diğer çıra ve kışın yaprak döken bitkilerle birlikte çoğunlukla gürgen (Carpinus spp.) ve kayın ağaçları (Fagus orientalis L.) gözlemlenir. $1500 \mathrm{~m}$ ve üzerinde ise saf veya karışı karaçam (Pinus nigra ssp. pallasiana) ve sarıçam (Pinus sylvestris L.) ormanları bulunur (Kuter, 2008). Bölgedeki yıllık ortalama sıcaklık $9.8^{\circ} \mathrm{C}$ 'dir. En soğuk ay $-0.8^{\circ} \mathrm{C}$ ortalama sicaklıkla Ocak iken en sicak ay $20^{\circ} \mathrm{C}$ ile Temmuz'dur. Kastamonu Meteoroloji İstasyonu verilerine göre yıllık ortalama yağış miktarı 486mm'dir. Dağ zirvelerinde yağış yaklaşık 1200mm civarındadır. 
İç Anadolu ikliminin etkisiyle yamaçlarda 1 metreyi bulan kar tabakası, 6 ay boyunca kalmaktadır (Aydinozu vd., 2011).

\subsection{MODIS - Landsat Veri Seti ve Görüntülerin Ön-işlenmesi}

Bu çalışmada toplam 13 adet MODIS - Landsat 7/8 görüntü çifti kullanılmış olup, bunlardan 8 tanesi DVM modellerin eğitilmesinde kullanılmış, geriye kalan 5 tanesi ise bağımsız test verisi olarak ayrılmıştır. Uydu görüntülerine ait detaylar Tablo 1'de verilmiştir.

Tablo 1. DVM modellerin eğitilmesinde ve testinde kullanılan Landsat 7/8 ve MODIS görüntü çiftleri.

\begin{tabular}{|c|c|c|c|c|}
\hline $\begin{array}{c}\text { Görüntü } \\
\text { Çiftleri }\end{array}$ & Görüntü Tarihi & $\begin{array}{l}\text { Görüntü Zamanı } \\
\text { Landsat/MODIS }\end{array}$ & $\begin{array}{c}\text { ETM+/OLI } \\
\text { İz/SIra } \\
\end{array}$ & $\begin{array}{c}\text { Analize Uygun } \\
\text { Piksel Sayısı } \\
\end{array}$ \\
\hline \multicolumn{5}{|c|}{ Eğitim Veri Seti } \\
\hline 1 & 07.03 .2000 & 08:19/08:55 & $177 / 32-\mathrm{L} 1 \mathrm{~T}$ & 3340 \\
\hline 2 & 23.12 .2001 & 08:15/08:45 & $177 / 32-\mathrm{L} 1 \mathrm{~T}$ & 9571 \\
\hline 3 & 02.02 .2014 & 08:28/09:30 & $177 / 32-\mathrm{L} 1 \mathrm{~T}$ & 15880 \\
\hline 4 & 18.02 .2014 & 08.28/07:55 & $177 / 32-\mathrm{L} 1 \mathrm{~T}$ & 12284 \\
\hline 5 & 04.01 .2015 & 08:27/09:30 & $177 / 32-\mathrm{L} 1 \mathrm{~T}$ & 5117 \\
\hline 6 & 25.03 .2015 & 08:26/07:55 & 177/32 - L1T & 14162 \\
\hline 7 & 15.01 .2016 & 08:28/08:45 & $177 / 32-\mathrm{L} 1 \mathrm{~T}$ & 14198 \\
\hline 8 & 28.04 .2016 & 08:26/07:55 & $177 / 32-\mathrm{L} 1 \mathrm{~T}$ & 14238 \\
\hline \multicolumn{5}{|c|}{ Test Veri Seti } \\
\hline A & 26.12.2002 & 08:15/08:45 & 177/32 - L1T & 10796 \\
\hline B & 06.04 .2005 & 08:16/08:40 & $177 / 32-\mathrm{L} 1 \mathrm{~T}$ & 15015 \\
\hline C & 22.01 .2007 & 08:17/08:40 & $177 / 32-\mathrm{L} 1 \mathrm{~T}$ & 18189 \\
\hline D & 09.03 .2015 & 08:26/07:55 & 177/32- L1T & 14916 \\
\hline $\mathbf{E}$ & 08.02 .2016 & 08:27/09:30 & $177 / 32-\mathrm{L} 1 \mathrm{~T}$ & 8579 \\
\hline
\end{tabular}

Analizlerde kullanılan tüm MODIS MOD2HKM görüntüleri (Xiong vd., 2006), ilgili Landsat görüntülerinin projeksiyonuyla eşleşmesi için WGS84 referanslı ortak bir UTM projeksiyonuna MODIS yeniden projeksiyonlandırma aracı (MODIS Reprojection Tool) (Dwyer ve Schmidt, 2006) kullanılarak yeniden projeksiyonlandırılmıştır. MODIS 1-7 bantlarına ait atmosfer üstü reflektans değerlerine ek olarak, NDSI, normalize fark vejetasyon indisi (normalized difference vegetation index - NDVI) (Eşitlik 2) ve Uluslararası Jeosfer-Biyosfer Programı (The International Geosphere-Biosphere Programme - IGBP) kapsamında MODIS MCD12Q1 ürününden (Friedl vd., 2010) elde edilen 500m mekansal çözünürlükteki arazi örtüsü bilgisi bağımsız değişkenler olarak kullanılmıştır. Dobreva ve Klein (2011)'de olduğu gibi MCD12Q1'deki orijinal arazi örtüsü sınıfları sekiz gruba ayrılmıştır ve su pikselleri maskelenmiştir. Bulutlu, bulut gölgesi, su ve kötü kaliteli pikseller, MODIS MOD09 kalite verisinden (Vermote vd., 2011) elde edilen mekansal maskeler yardımıyla analizlerden çıkarılmıştır.

$$
\mathrm{NDVI}_{\text {MODIS }}=\frac{\text { bant } 2-\text { bant } 1}{\text { bant } 2+\text { bant } 1} \text {. }
$$

Analizlerde kullanılan tüm Landsat 7/8 bantlarına ait ham sayısal değerler (DNs) atmosfer üstü reflektans değerlerine dönüştürülmüştür. ETM+ sensörünün tarama çizgi düzelticisi (Scan Line Corrector - SLC), 31 Mayıs 2003'te kalıcı olarak arızalandığından görüntü başına piksellerin yaklaşık \%22'sinde tarama yapılamamakta ve bu durum ETM+ verilerinin bilimsel uygulamalarını ciddi şekilde kısıtlamaktadır (Chen vd., 2011). Bu nedenle ETM+ sensörünün SLC arızasından ötürü ilgili her bir görüntüdeki boşluklar, Scaramuzza vd. (2004) tarafından önerilen metodoloji ile doldurulmuştur. Referans EKKA haritaları daha yüksek mekânsal çözünürlüklü Landsat 7/8 görüntülerinin Hall vd. (1998) tarafından orijinal MODIS ikili kar algoritmasının yoğun ormanlık alanlardaki doğruluğunu artırmak amacıyla geliştirilen ikinci versiyonu kullanılarak elde edilmiştir. MODIS ikili kar haritalama algoritmasına eşdeğer olan bu ikili sınıflandırmada bir pikselin kar olarak etiketlenmesi için, NDSI $\geq 0.4$, ETM+ bant 2 reflektans $\geq \% 10$, ETM+ bant 4 reflektans $>\% 11$ ve ayrıca düzensiz NDSI-NDVI karar bölgesi koşulunun aynı anda sağlanması gerekmektedir. Daha sonra, her bir MODIS pikselinin merkezinde yer alan 500m yarıçaplı dairesel bir alan içindeki kar etiketli Landsat piksellerinin yüzdesi hesaplanarak, her MODIS pikseli için EKKA değeri elde edilmiştir. Literatürde yer alan çalışmalarda bildirilen MODIS coğrafi konum belirsizlikleri nedeniyle (Wolfe, 2006) tam bir MODIS pikseli içine düşen EKKA miktarını hesaplamak yerine, kar fraksiyonu daha geniş bir alan içinde hesaplanmıştır ki, bu yöntem MODIS coğrafi konum belirsizliklerini minimize etmek için yaygın olarak kullanılan bir yaklaşımdır 
(Kuter vd., 2018b; Painter vd., 2009). Tablo 2, analizlerde kullanılan bağımsız ve bağımlı değişkenlerle ilgili ayrıntılı bilgi vermektedir.

Tablo 2. DVM modellerin oluşturulmasında kullanılan değişkenler.

\begin{tabular}{|c|c|}
\hline \multicolumn{2}{|c|}{ Bağımsız değișken olarak kullanılan MODIS verileri } \\
\hline Bant 1 & $620-670 \mathrm{~nm}$ \\
\hline Bant 2 & $841-876 \mathrm{~nm}$ \\
\hline Bant 3 & $459-479 \mathrm{~nm}$ \\
\hline Bant 4 & $545-565 \mathrm{~nm}$ \\
\hline Bant 5 & $1230-1250 \mathrm{~nm}$ \\
\hline Bant 6 & $1628-1652 \mathrm{~nm}$ \\
\hline Bant 7 & $2105-2155 \mathrm{~nm}$ \\
\hline NDSI & $($ bant $4-$ bant 6$) /($ bant $4+$ bant 6$)$ \\
\hline NDVI & $($ bant $2-$ bant 1$) /($ bant $2+$ bant 1$)$ \\
\hline Arazi Sınıfı (IGBP) & MODIS MCD12Q1 \\
\hline \multicolumn{2}{|c|}{ Referans EKKA haritalarını üretmek için kulanılan ETM+ / OLI bantları } \\
\hline Bant $2 / 3$ & $0,52-0,60 / 0,53-0,59 \mu \mathrm{m}$ \\
\hline Bant 4 / 5 & $0,77-0,90 / 0,85-0,88 \mu \mathrm{m}$ \\
\hline Bant 5 / 6 & $1,55-1,75 / 1,57-1,65 \mu \mathrm{m}$ \\
\hline
\end{tabular}

\subsection{Destek Vektör Makineleri (DVM)}

Bu alt bölümde Haykin (2009), Vapnik (1995), Richards ve Jia (2006) ile Smola ve Schölkopf (2004)'e dayanılarak DVM ile ilgili genel bir özet sunulmaktadır.

En basit durum göz önüne alındığında, DVM doğrusal bir ikili sınıflandırıcıdır. DVM eğitim aşaması sonrasında bir test örneği verildiğinde iki olası etiketten birini sınıf olarak atar. UA'daki bir sınıflandırma için etiketlenecek test verileri, genellikle çok spektralı ya da hiper spektralı görüntülerin her bir bandında bulunan her bir piksele ait sayısal değerlerdir (reflektans, radyans ya da ham sayısal değer (Digital Number - DN).

Eğitim verisi için, ilgili özelliklerle (yani, bağımsız değişkenler) birlikte girdi vektörleri setinin $\boldsymbol{x}_{i}$ tarafından verildiğini varsayalım. Her bir vektör $\mathbf{x} \in \mathbf{R}^{N}$ 'nin $N$-boyutlu uzay olduğu ve $i$ 'nin mevcut örneklerin sayıs olduğu yerde, $\left(\mathbf{x}_{1}, y_{1}\right), \ldots,\left(\mathbf{x}_{i}, y_{i}\right)$ gibi $y_{i}$ tarafından simgelenen ilgili etiketle (yani, sınıf) ilişkilendirilmektedir. En basit ikili sınıflandırma durumunda, $y_{i}$ sadece iki muhtemel etiket alabilir, +1 ve -1 . İkili sınıflandırıcı DVM'deki öğrenme görevinin temel amacı: $(i)$ hiper-düzlemin bir tarafındaki veri noktalarının $y_{i}=+1$, diğer tarafındakilerin ise $y_{i}=-1$ olarak etiketlendiği ve (ii) hiper-düzlemin iki sınıfın etiketlenen noktalarına olan uzaklığının maksimize edildiği bir hiper-düzleme karar vermektir. Yanlış sınıflandırmaları en aza indiren maksimum marjinli en uygun ayırıcı hiper-düzlemin konumu, iki sınıfa en yakın eğitim noktalarına komşu olan ayırıcı hiper-düzleme paralel olan iki hiper-düzlemce (yani, destek vektörler) tanımlanır (Bakınız Şekil 2). En uygun hiper-düzleme paralel iki hiper-düzlem şu şekilde ifade edilir:

$$
\begin{array}{ll}
\mathbf{w} \cdot \mathbf{x}_{i}+b \geq+1, & y_{i}=+1, \\
\mathbf{w} \cdot \mathbf{x}_{i}+b \geq-1, & y_{i}=-1, \\
(i=1,2, \ldots, k), &
\end{array}
$$

“.” nokta ya da skalar çarpımı, $b$ hiper-düzlemin orijinden olan uzaklığını, $\mathbf{x}_{i}$, bağımsız değişkenler vektörünü ve $\mathbf{w}=\left(w_{1}, \ldots, w_{N}\right)^{T}$ en uygun ayırıcı hiper-düzlemin yönünü tayin eden $N$ sayıdaki elemanın ağırlık vektörünü simgelemektedir. İfade (3)'deki iki eşitsizlik aşağıdaki tek eşitsizlik içinde yazılabilmektedir:

$$
y_{i}\left[\mathbf{w} \cdot \mathbf{x}_{i}+b\right] \geq 1 \quad(i=1,2, \ldots, k)
$$




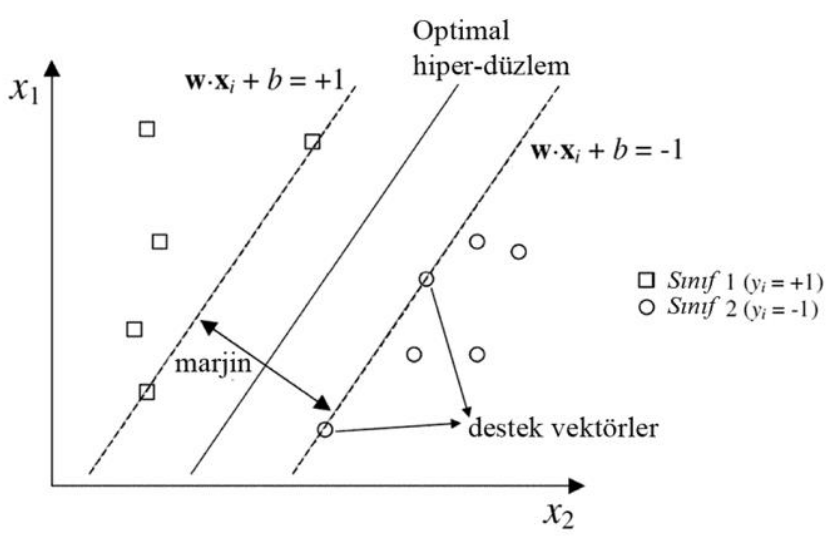

Şekil 2. Destek vektörleri tarafından tanımlanan en uygun ayırıcı hiper-düzlem (Richards ve Jia, 2006).

Maksimum marjinli en uygun ayırıcı hiper-düzlem, İfade (4)'de verilen eşitsizlik kısıtlamasıyla birlikte aşağıdaki eşitlikte gösterildiği gibi w'nun normunun minimize edilmesiyle elde edilebilir:

$$
F(\mathbf{w})=\frac{1}{2}(\mathbf{w} \cdot \mathbf{w})
$$

$\mathrm{Bu}$ durum Eşitlik (5)'deki hedef fonksiyonunun Lagrange çarpanları kullanılmak suretiyle İfade (4)'teki kısıtlara tabi olarak minimize edildiği bir kısıtlamalı optimizasyon problemidir. Bazı yeniden düzenlemeler ve değişikliklerden sonra en uygun ayırıcı hiper-düzlemi tanımlayan karar kuralı şöyledir:

$$
g(\mathbf{x})=\operatorname{sign}\left(\sum_{i}^{r} y_{i} \alpha_{i}^{0} K\left(\mathbf{x}, \mathbf{x}_{i}\right)-b^{0}\right),
$$

Burada her bir $r$ eğitim durumu için sınıf üyeliğinin tanımı olan $y_{i}$ ile birlikte duruma ait çıktıyı temsil eden bir $\mathbf{x}_{i}$ vektörü var olup, $\alpha_{i} \geq 0,(i=1,2, \ldots, r)$ Lagrange çarpanlarını, $K\left(\mathbf{x}, \mathbf{x}_{i}\right)$ ise veri noktalarının doğrusal bir hiper-düzlem tarafından ayrılabileceği şekilde dağılımını sağlayan kernel fonksiyonunu simgelemektedir.

Doğrusal DVM uygulaması, girdi verisinin doğrusal olarak ayrılabileceği varsayımına dayanmakta olup, bu koşul çok veya hiper spektralı UA görüntülerinde nerdeyse hiç sağlanmamaktadır. Buna ek olarak, UA görüntülerindeki sınıfların mekânsal ve spektral olarak çakışması doğrusal karar sınırlarının sınıfları yüksek doğrulukla ayırmasını zorlaştırmaktadır. Bu tür sıkıntıların üstesinden gelebilmek için yumuşak marjin ve kernel metodları geliştirilmiştir. Radyal taban fonksiyonu (Radial Basis Function - RBF), doğrusal, kuadratik ve polinom kerneller ham veriyi çok boyutlu özellik uzayına dönüştürmede sıklıkla kullanılmaktadır (Mountrakis vd., 2011; Pal ve Mather, 2005).

Başlangıçta örüntü tanımlama görevleri için geliştirilmiş olsa da, DVM'ler regresyonda da oldukça iyi bir performans sergilemiştir. DVM regresyonunda ana hedef, tüm eğitim verileri için gerçekte elde edilen $y_{i}$ hedef değerlerinden en çok $\varepsilon$ kadar sapmaya sahip olan ve aynı zamanda da mümkün olduğunca düz olan bir $f(\mathbf{x})$ fonksiyonu bulmaktır. $\varepsilon$ 'den daha az olan hatalar göz ardı edilebilir olarak görülmekte, bundan büyük olan sapmalar ise kabul edilmemektedir. Bu durumda $f(\mathbf{x})$ aşağıdaki ifadeye dönüşür:

$$
f(\mathbf{x})=\mathbf{w} \cdot \mathbf{x}_{i}+b, \mathbf{w} \in \mathbf{X}, b \in \mathbf{R}
$$

burada X girdi değişkenleri uzayını simgelemektedir. Eşitlik (7)’ye göre, “düzlük” küçük w cinsinden ifade edilebilmekte olup, bunu sağlamanın bir yolu ise bir konveks optimizasyon problemi olarak yeniden yazılabilecek olan $\|\mathbf{w}\|^{2}=(\mathbf{w} \cdot \mathbf{w})$ 'yi minimize etmektir: 


$$
\begin{aligned}
& \text { minimize } \frac{1}{2}\|\mathbf{w}\|^{2}, \\
& \text { kisitlar }\left\{\begin{array}{l}
y_{i}-\mathbf{w} \cdot \mathbf{x}_{i}-b \leq \varepsilon, \\
\mathbf{w} \cdot \mathbf{x}_{i}+b-y_{i} \leq \varepsilon,
\end{array}\right. \\
& (i=1,2, \ldots, N)
\end{aligned}
$$

İfade (8), böyle bir $f(\mathbf{x})$ fonksiyonunun var olduğunu ve bu fonksiyonun bütün $\left(\mathbf{x}_{i}, y_{i}\right)$ çiftlerini $\varepsilon$ hassasiyetiyle tahminleyeceğini, yani bu konveks optimizasyon probleminin "uygulanabilir" olduğunu üstü kapalı olarak varsaymaktadır. Bazı hatalara müsaade edilebilen uygulanamaz senaryo durumunda, yapay değişkenler $\xi_{i}, \xi_{i}^{*}$, İfade (8)'deki optimizasyon problemine ait diğer uygulanamaz kısıtların üstesinden gelmek için kullanılabilmekte olup, bu yöntem aynı zamanda "yumuşak marjin” metodu olarak bilinmektedir. Sonuç olarak Vapnik (1995)'de verilen aşağıdaki formülasyon elde edilmektedir:

$$
\begin{gathered}
\operatorname{minimize} \frac{1}{2}\|\mathbf{w}\|^{2}+C \sum_{i=1}^{l}\left(\xi_{i}+\xi_{i}^{*}\right), \\
\text { kisitlar }\left\{\begin{array}{l}
y_{i}-\mathbf{w} \cdot \mathbf{x}_{i}-b \leq \varepsilon+\xi_{i}, \\
\mathbf{w} \cdot \mathbf{x}_{i}+b-y_{i} \leq \varepsilon+\xi_{i}^{*}, \\
\xi_{i}, \xi_{i}^{*} \geq 0 .
\end{array}\right.
\end{gathered}
$$

Sabit $C>0, f(\mathbf{x})$ 'in düzlüğü ile $\varepsilon$ 'den daha büyük sapmaların tölere edilebileceği miktar arasındaki ödünleşmeyi kontrol eder. Bu durum bizi, Şekil 3'de grafiksel olarak gösterilen $\varepsilon$ 'den etkilenmeyen $|\xi|_{\varepsilon}$ hata hesaplama fonksiyonuna götürmekte olup, şu şekilde ifade edilmektedir:

$$
|\xi|_{\varepsilon}:= \begin{cases}0, & \text { e⿳̆ }|\xi| \leq \varepsilon \\ |\xi|-\varepsilon, & \text { aksi halde. }\end{cases}
$$
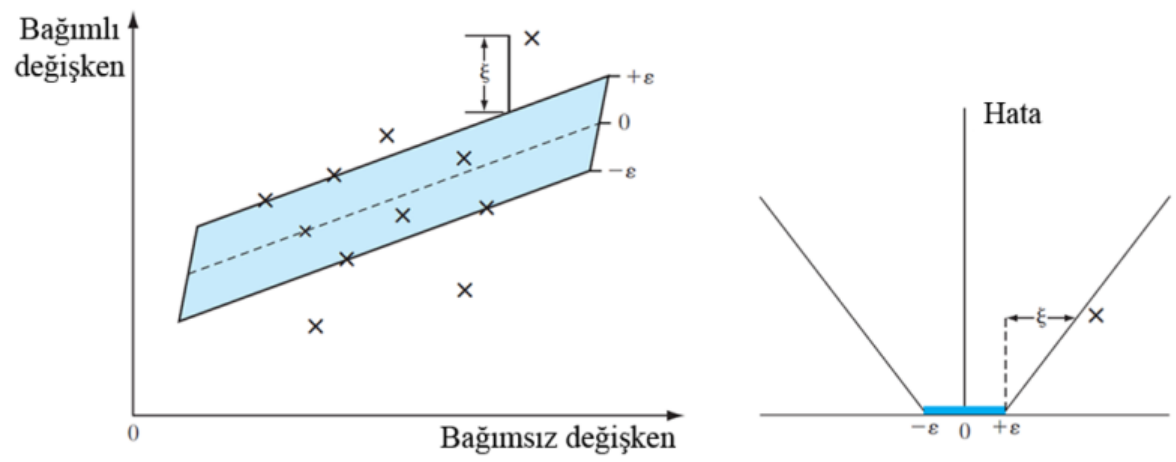

Şekil 3. Doğrusal bir DVM için yumuşak marjin hatası gösterimi (Haykin, 2009).

\subsection{Deneysel Tasarım}

\subsection{1 Örneklem Türü ve Örneklem Boyutu}

Eğitim veri setindeki işlenen görüntülerden elde edilen kullanılabilir piksellerin tümü 88790 gözlemden oluşan tek bir veri setinde birleştirilmiş ve örneklem çerçevesi olarak kullanılmıştır. DVM modellerinin doğruluğu üzerinde örneklem boyutunun etkisini incelemek için küçük, orta ve büyük olmak üzere üç farklı boyuttaki örnekler, bu örneklem çerçevesinden elde edilmiştir. Küçük, orta ve büyük boyutlu örnekler toplam gözlemlerin sırasıyla \%2, \%15 ve \%30'unu içermektedir. Her bir piksel için on bağımsız değişkenden oluşan eğitim verisi, MOD02HKM ilk yedi bandına ait atmosfer üstü reflektans değerlerini, NDSI, NDVI ve arazi örtüsü sınıfını içermektedir. 
Örneklem boyutunun etkisine ek olarak örneklem türünün etkisi de incelenmiștir. İlk olarak, üç farklı boyuttaki örnekler basit rastgele örnekleme ile seçilmiştir. Sonra tabakalı rastgele örnekleme kullanılmıştır. Modellerin herhangi bir EKKA değerine yanlı olmasını engellemek için 0,0 ile 1,0 arasındaki EKKA değerleri için 0,1 aralıklarla tabakalama uygulanmıştır. Yukarıda bahsedilen süreç sayesinde altı farklı türde model eğitim seti oluşturulmuş olup, bunların ayrıntıları Tablo 3'te verilmektedir.

Tablo 3. Örneklem boyutuna ve örneklem türüne göre eğitim piksellerinin sayısı.

\begin{tabular}{ccc}
\hline $\begin{array}{c}\text { Örneklem için kullanılabilecek toplam piksel } \\
\text { (gözlem) sayısı }\end{array}$ & \multicolumn{2}{c}{88790} \\
\hline Örneklem Boyutu & Örneklem Türü & $\begin{array}{c}\text { Örneklenen Piksel } \\
\text { Sayısı }\end{array}$ \\
\hline \multirow{2}{*}{ Küçük (2\%) } & BR & 1277 \\
& TR_EKKA & 1211 \\
Orta (15\%) & BR & 9361 \\
& TR_EKKA & 9308 \\
Büyük (30\%) & BR & 18600 \\
\hline BR: Basit rastgele örnekleme, TR_EKKA: Etkili kar kaplı alan bakımından tabakalandırılmıs rastgele
\end{tabular}
örnekleme.

\subsubsection{DVM Modellerin Eğitimi ve Performans Ölçütleri}

Başarılı bir DVM uygulaması, DVM modelin eğitiminde anahtar rol oynayan iki parametrenin optimum seçimini gerektirir. Bunlar kernel fonksiyonu ve ödünleşme düzenleyicisi $C$ 'dir. Bununla birlikte bu parametrelerin seçimi için genel olarak kabul gören bir yöntem yoktur, bu da genellikle bir temel denemeyanılma yaklaşımına neden olur (Mountrakis vd., 2011; Yuan ve Lee, 2015).

DVM uygulamalarında kullanılan kernel fonksiyonları doğrusal, polinom, RBF ve sigmoid kerneller olmak üzere dört ana kategori altında gruplandırılabilir. UA literatüründe $\operatorname{RBF}\left(e^{-\gamma\left\|\left(\mathbf{x}-\mathbf{x}_{i}\right)\right\|^{2}}\right)$, ve polinom kernel $((\mathbf{x} \cdot \mathbf{y})+1)^{d}$, sıklıkla tercih edilmektedir (Pal ve Mather, 2005). RBF kerneli, için kernel genişliği $\gamma$ ve $C$ tanımlanmalıdır. Öte yandan polinom kerneller için, polinomun derecesi $d$ ve $C$ belirlenmelidir. Bu parametreler için en uygun değerleri seçmek için 1zgara arama (yani, grid search) yöntemi Kavzoglu ve Colkesen (2009) tarafından önerildiği gibi kullanılmıştır. Bu yaklaşımda $(C, \gamma)$ ve $(C, d)$ 'nin üssel olarak artan serisi içinde daha kaba bir arama uygulanmaktadır ve ızgara aralığında en uygun bölge belirlendiğinde bu bölge içinde daha hassas bir ızgara araması yürütülmektedir. RBF kernel genişliği için $\gamma 10^{-3}-10^{3}$ aralığında seçilirken, $C\left\{2^{-15}, \ldots 2^{0}, \ldots, 2^{15}\right\}$ aralığındaki değerleri almıştır. Polinom kernel için $d$ derecesi $\{2,3,4\}$ setinden değerler almıştır. DVM regresyon modellerinin performansı hataların kareleri ortalamasının karekökü (Root Mean Squared Error - RMSE) ve Pearson korelasyon katsayısı $(R)$ kullanılarak değerlendirilmiştir:

$$
\begin{gathered}
\mathrm{RMSE}=\sqrt{\frac{\sum_{i=1}^{N}\left(\hat{y}_{i}-y_{i}\right)^{2}}{N}}, \\
R=\frac{N \sum_{i=1}^{N} y_{i} \hat{y}_{i}-\sum_{i=1}^{N} y_{i} \sum_{i=1}^{N} \hat{y}_{i}}{\sqrt{N \sum_{i=1}^{N} y_{i}^{2}-\left(\sum_{i=1}^{N} y_{i}\right)^{2}} \sqrt{N \sum_{i=1}^{N} \hat{y}_{i}^{2}-\left(\sum_{i=1}^{N} \hat{y}_{i}\right)^{2}}} .
\end{gathered}
$$

Eşitlik (11) ve (12)'de, $N$ toplam gözlem sayısını, $y_{i}$, $i$. gözleme ait referans değerini, ve $\hat{y}_{i}$ ise $i$. gözleme ait tahmin edilen değeri belirtmektedir. 


\section{Bulgular ve Tartışma}

\subsection{Eğitim Verisi Üzerinde DVM}

DVM modellerin eğitimi boyunca her bir örneklem türündeki eğitim verisi \%70 eğitim ve \%30 doğrulama verisi şeklinde iki alt kümeye ayrılmıştır. Her bir örneklem türü için eğitim evresi boyunca doğrulama verisi üzerinde $R$ bakımından en yüksek performanslı DVM modeli seçilmiştir. Beş farklı DVM modelinin eğitim performansı kıyaslandığında, oldukça benzer sonuçlar verdiği gözlemlenmektedir. RBF, doğrusal, 2., 3. ve 4. derece polinom DVM modellerin $R$ değerleri sirasiyla $0.9790,0.9605,0.9766,0.9790$ ve 0.9784 olup, eğitim veri seti üzerinde gayet iyi ve oldukça benzer sonuçlar vermiştir (Tablo 4). Her bir örneklem türü ve örnek boyutu için modellerin eğitim sürecinde \%30'luk doğrulama verisi üzerinde en iyi $R$ değerini veren seçilmiştir.

Tablo 4. DVM modellerin eğitim performans değerleri.

\begin{tabular}{|c|c|c|c|c|c|c|}
\hline \multirow{2}{*}{ Kernel } & \multirow{2}{*}{ Örneklem türü } & \multirow{2}{*}{$\begin{array}{l}\text { Örneklem } \\
\text { boyutu }\end{array}$} & \multicolumn{2}{|c|}{ Eğitim } & \multicolumn{2}{|c|}{ Doğrulama } \\
\hline & & & RMSE & $\boldsymbol{R}$ & RMSE & $\boldsymbol{R}$ \\
\hline \multirow{6}{*}{ 空 } & \multirow{3}{*}{ BR } & Küçük & 0.0880 & 0.9791 & 0.0914 & 0.9775 \\
\hline & & Orta & 0.1236 & 0.9576 & 0.1266 & 0.9549 \\
\hline & & Büyük & 0.0900 & 0.9778 & 0.0947 & 0.9748 \\
\hline & \multirow{3}{*}{ TR_EKKA } & Küçük & 0.1303 & 0.9516 & 0.1373 & 0.9503 \\
\hline & & Orta & 0.0809 & 0.9821 & 0.0890 & 0.9785 \\
\hline & & Büyük & 0.0908 & 0.9772 & 0.0875 & 0.9790 \\
\hline \multirow{6}{*}{ 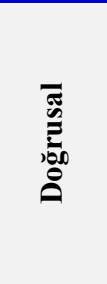 } & \multirow{3}{*}{ BR } & Küçük & 0.1213 & 0.9595 & 0.1223 & 0.9595 \\
\hline & & Orta & 0.1201 & 0.9601 & 0.1230 & 0.9576 \\
\hline & & Büyük & 0.1208 & 0.9597 & 0.1244 & 0.9561 \\
\hline & \multirow{3}{*}{ TR_EKKA } & Küçük & 0.1211 & 0.9581 & 0.1311 & 0.9544 \\
\hline & & Orta & 0.1228 & 0.9581 & 0.1236 & 0.9583 \\
\hline & & Büyük & 0.1218 & 0.9586 & 0.1195 & 0.9605 \\
\hline \multirow{6}{*}{ 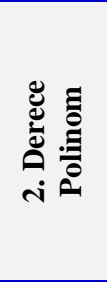 } & \multirow{3}{*}{$\mathbf{B R}$} & Küçük & 0.0942 & 0.9760 & 0.0950 & 0.9766 \\
\hline & & Orta & 0.0991 & 0.9732 & 0.0995 & 0.9725 \\
\hline & & Büyük & 0.0973 & 0.9740 & 0.1005 & 0.9715 \\
\hline & \multirow{3}{*}{ TR_EKKA } & Küçük & 0.0956 & 0.9742 & 0.1096 & 0.9686 \\
\hline & & Orta & 0.1000 & 0.9723 & 0.1005 & 0.9725 \\
\hline & & Büyük & 0.0973 & 0.9741 & 0.0942 & 0.9759 \\
\hline \multirow{6}{*}{ 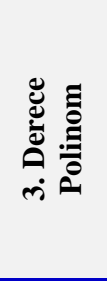 } & \multirow{3}{*}{$\mathbf{B R}$} & Küçük & 0.0870 & 0.9796 & 0.0907 & 0.9787 \\
\hline & & Orta & 0.0919 & 0.9768 & 0.0937 & 0.9755 \\
\hline & & Büyük & 0.0899 & 0.9778 & 0.0942 & 0.9750 \\
\hline & \multirow{3}{*}{ TR_EKKA } & Küçük & 0.0876 & 0.9783 & 0.1036 & 0.9718 \\
\hline & & Orta & 0.0909 & 0.9771 & 0.0914 & 0.9772 \\
\hline & & Büyük & 0.0911 & 0.9771 & 0.0877 & 0.9790 \\
\hline \multirow{6}{*}{ 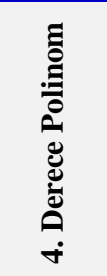 } & \multirow{3}{*}{ BR } & Küçük & 0.0867 & 0.9795 & 0.0904 & 0.9784 \\
\hline & & Orta & 0.0928 & 0.9767 & 0.0940 & 0.9757 \\
\hline & & Büyük & 0.0950 & 0.9764 & 0.0995 & 0.9732 \\
\hline & \multirow{3}{*}{ TR_EKKA } & Küçük & 0.0920 & 0.9760 & 0.1051 & 0.9709 \\
\hline & & Orta & 0.0920 & 0.9765 & 0.0925 & 0.9766 \\
\hline & & Büyük & 0.0969 & 0.9756 & 0.0940 & 0.9772 \\
\hline
\end{tabular}

*Kalın yazı tipiyle belirtilen $R$ değerleri her bir tür için en iyi eğitim performansını göstermektedir.

RBF, doğrusal ve 3. dereceden polinom için en iyi eğitim performansları büyük boyutlu eğitim verileriyle elde edilmiştir, EKKA bakımından tabakalı rastgele örnekleme tarafından örneklendirilmiştir. 2. derece ve 4. derece polinomlar basit rastgele örneklemeyle seçilen küçük boyutlu veri üzerinde en iyi eğitim performansını vermiştir. Ancak her bir model türü hem örneklem türüne hem de örneklem boyutuna göre ayrı ayrı değerlendirildiğinde ilgili RMSE ve $R$ değerleri bakımından önemli bir değişiklik gözlemlenmemiştir. Bu sonuçlar, model oluşturma sürecinde kullanılan eğitim verileri bağımsız değişkenler ile bunlara ait bağımlı 
değişken arasındaki ilişkiyi yeterince temsil ediyorsa eğitim verisinin boyutu ve örneklem türünün eğitim evresinde DVM'in tahminleyici performansı üzerinde etkisi olmadığını göstermektedir. Model eğitimleri sonucunda elde edilen optimal kernel parametreleri Tablo 5 'te verilmiştir.

Tablo 5. Kernel fonksiyonları için belirlenen optimal değerler ve ilgili modele ait eğitim $R$ değeri.

\begin{tabular}{lccc}
\hline Kernel Fonksiyonu & $\boldsymbol{C}$ & $\boldsymbol{\gamma}$ & $\boldsymbol{R}$ \\
\hline RBF & 260,8576 & 4,2855 & 0,9790 \\
Doğrusal & 9,1396 & - & 0,9605 \\
2. Derece Polinom & 18,2176 & - & 0,9766 \\
3. Derece Polinom & 0,2500 & - & 0,9790 \\
4. Derece Polinom & 0,0677 & - & 0,9784 \\
\hline
\end{tabular}

\subsection{Test Verisi Üzerinde DVM}

Modellerin eğitimi sırasında kullanılmayan bağımsız test verisi, DVM EKKA modellerinin performansını objektif olarak değerlendirmek için en uygun veri setidir. Bağımsız test verisi, Tablo 1'de verilen 5 ayrı görüntü verisinden ve bunların birleştirilmesiyle elde edilen birleşik test verisi olmak üzere toplam 6 veri setinden oluşmaktadır. En iyi eğitim performansına göre Tablo 6'da bağımsız test verisi üzerinde elde edilen DVM sonuçları sunulmaktadır. Her biri kalın harfle yazılmış dizi her bir test setindeki ilgili $R$ ve RMSE değerlerini göstermektedir. Bu değerler elde edilen en iyi eğitim performansını veren ilgili DVM modeli baz alınarak hesaplanmıştır. İlk bakışta genel bir çıkarım olarak, eğitim aşamasında gözlemlenen en iyi eğitim performansına sahip DVM modellerinin $R$ değerleri RBF kernel için 0,9139 ile 0,9681, doğrusal kernel için 0,9168 ile 0,9712, 2. derece polinom kernel için 0,8886 ile 0,9716, 3. derece polinom kernel için 0,8438 ile 0,9523, 4. derece polinom kernel için ise 0,8719 ve 0,9524 aralığında bulunmaktadır. En iyi eğitim performansına sahip DVM modellerinin RMSE değerleri RBF için 0,1077 - 0,2825, doğrusal için 0,0792 - 0,3015, 2. derece polinom için $0,1105-0,2400,3$. derece polinom için 0,1140 - 0,2723, ve son olarak, 4. derece polinom için $0,1410-0,2502$ aralığında bulunmaktadır.

DVM modellerin performansları sırasıyla Tablo 7'de verildiği üzere eğitim boyunca geçen işlemci süresine (CPU zamanı) dayalı verimlilik bakımından değerlendirildiğinde, hem model karmaşıklığının hem de eğitim verisi boyutundaki artışın CPU zamanında artışla sonuçlandığı gözlemlenmektedir. Eğitim verisinin boyutunun küçük olduğu yerde seçilen RBF modeli için ortalama eğitim zamanı 278,79 saniyedir. Büyük boyutlu veri ile eğitimi yapılan 3. dereceden polinom modelinin eğitimi için harcanan ortalama CPU zamanı ise 106014,65 saniyedir (Tablo 7). Bu çalışmadaki analizler Intel Core i7 3537U 2,00 GHz işlemcili ve 6 GB RAM'e sahip bir bilgisayar kullanılarak yapılmıştır.

Tablo 8'de sunulan sonuçlara göre MODIS'in kendi EKKA ürünü olan MOD10A1 ürünü (Hall vd., 2006) bağımsız test verisi üzerinde en zayıf performansı vermektedir. Buna karşın EKKA haritalaması performanslarında DVM modelleri arasında belirgin farklar görülmemektedir. Şekil 4'de Tablo 8'de verilen sonuçlara ait saçılım grafikleri ayrıca sunulmaktadır. Ancak DVM modellerin ve MOD10A1 ürününün performansında istatiksel bakımdan anlamlı farklılıklar olup olmadığına karar vermek için tekrarlanan varyans analizi (repeated analysis of variance - RANOVA) (Davis, 2002) yapılarak, aşağıdaki hipotezler her bir performans ölçütü için ayrı ayrı test edilmiştir:

$$
\begin{aligned}
& H_{0}: M_{\text {Model }_{i}}=M_{\text {Model }_{j}}, \\
& H_{1}: M_{\text {Model }_{i}} \neq M_{\text {Model }_{j}} .
\end{aligned}
$$

Burada, $M_{\text {Model }_{i}}$, karşılaştırmalarda kullanılan ilgili modelin (yani, DVM ya da MOD10A1) performans ölçütünün (yani, RMSE ve $R$ ) beklenen değerini göstermektedir. RANOVA boyunca $\alpha=0,05$ önem seviyesinde Fisher'in en az anlamlı fark (Least Significant Difference - LSD) (Dodge, 2008) testi de istatistiksel bakımdan farklı modelleri tanımlamak için uygulanmıştır. RANOVA testinin sonuçları Tablo 9'da verilmektedir. Çiftler halinde yapılan karşılaştırmaların sonuçları RBF, doğrusal ve 2., 3. ve 4. dereceden polinom modelleri arasında istatistiki açıdan önemli bir fark olmadığını ortaya çıkarmakta, ancak bütün test veri setlerinde MOD10A1 ürününden daha iyi performans sergilediklerini göstermektedir. 
Tablo 6. RBF, doğrusal, 2. 3. ve 4. derece Polinom kernel fonksiyonu kullanan DVM modellerinin beş bağımsız test görüntüsü ve toplamda 67495 pikselden oluşan birleşik test veri seti üzerindeki performansı.

\begin{tabular}{|c|c|c|c|c|c|c|c|c|c|c|c|c|c|c|}
\hline \multirow{2}{*}{ Model } & \multirow{2}{*}{\multicolumn{2}{|c|}{ Örneklem türü }} & \multicolumn{2}{|c|}{ A } & \multicolumn{2}{|c|}{ B } & \multicolumn{2}{|c|}{ C } & \multicolumn{2}{|c|}{ D } & \multicolumn{2}{|c|}{$\mathbf{E}$} & \multicolumn{2}{|c|}{ Birleşik } \\
\hline & & & RMSE & $\boldsymbol{R}$ & RMSE & $\boldsymbol{R}$ & RMSE & $R$ & RMSE & $\boldsymbol{R}$ & RMSE & $\boldsymbol{R}$ & RMSE & $R$ \\
\hline \multirow{6}{*}{ 音 } & \multirow{3}{*}{ BR } & $\mathbf{K}$ & 0,1927 & 0,9416 & 0,0946 & 0,9706 & 0,1407 & 0,9501 & 0,1020 & 0,8471 & 0,1968 & 0,9081 & 0,1431 & 0,9528 \\
\hline & & O & 0,2350 & 0,9399 & 0,1054 & 0,9688 & 0,1253 & 0,9556 & 0,0953 & 0,9180 & 0,1428 & 0,9374 & 0,1419 & 0,9514 \\
\hline & & B & 0,2910 & 0,9346 & 0,1198 & 0,9678 & 0,1766 & 0,9429 & 0,1082 & 0,8524 & 0,2249 & 0,9073 & 0,1848 & 0,9427 \\
\hline & \multirow{3}{*}{$\begin{array}{c}\text { TR } \\
\text { EKKA }\end{array}$} & $\mathbf{K}$ & 0,3092 & 0,9442 & 0,1358 & 0,9635 & 0,1420 & 0,9516 & 0,1247 & 0,9184 & 0,1535 & 0,9326 & 0,1768 & 0,9389 \\
\hline & & $\mathbf{O}$ & 0,2490 & 0,8695 & 0,2099 & 0,8451 & 0,3028 & 0,8021 & 0,1145 & 0,8040 & 0,2393 & 0,8384 & 0,2337 & 0,8714 \\
\hline & & B & $\mathbf{0 , 2 8 2 5}$ & $\mathbf{0 , 9 3 7 9}$ & 0,1212 & 0,9681 & $\mathbf{0 , 1 7 8 5}$ & 0,9431 & $\mathbf{0 , 1 0 7 7}$ & $\mathbf{0 , 8 5 8 8}$ & 0,2196 & $\mathbf{0 , 9 1 3 9}$ & 0,1825 & $\mathbf{0 , 9 4 5 7}$ \\
\hline \multirow{6}{*}{ 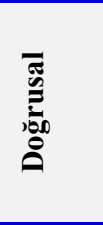 } & \multirow{3}{*}{ BR } & $\mathbf{K}$ & 0,2825 & 0,9166 & 0,0923 & 0,9716 & 0,1275 & 0,9541 & 0,0804 & 0,9164 & 0,1448 & 0,9357 & 0,1521 & 0,9399 \\
\hline & & $\mathbf{O}$ & 0,3040 & 0,9182 & 0,0951 & 0,9698 & 0,1246 & 0,9561 & 0,0787 & 0,9159 & 0,1432 & 0,9372 & 0,1580 & 0,9355 \\
\hline & & B & 0,2989 & 0,9187 & 0,0937 & 0,9703 & 0,1247 & 0,9560 & 0,0784 & 0,9171 & 0,1429 & 0,9375 & 0,1562 & 0,9372 \\
\hline & \multirow{3}{*}{$\begin{array}{c}\text { TR } \\
\text { EKKA }\end{array}$} & $\mathbf{K}$ & 0,3281 & 0,9232 & 0,0973 & 0,9678 & 0,1246 & 0,9565 & 0,0788 & 0,9147 & 0,1448 & 0,9364 & 0,1659 & 0,9316 \\
\hline & & $\mathbf{O}$ & 0,3045 & 0,9147 & 0,0925 & 0,9712 & 0,1282 & 0,9536 & 0,0783 & 0,9188 & 0,1418 & 0,9384 & 0,1583 & 0,9350 \\
\hline & & B & $\mathbf{0 , 3 0 1 5}$ & 0,9168 & $\mathbf{0 , 0 9 2 3}$ & $\mathbf{0 , 9 7 1 2}$ & 0,1268 & $\mathbf{0 , 9 5 4 5}$ & $\mathbf{0 , 0 7 9 2}$ & $\mathbf{0 , 9 1 8 2}$ & 0,1425 & $\mathbf{0 , 9 3 7 8}$ & 0,1573 & $\mathbf{0 , 9 3 7 1}$ \\
\hline \multirow{6}{*}{ 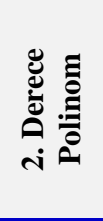 } & \multirow{3}{*}{ BR } & $\mathbf{K}$ & 0,2046 & $\mathbf{0 , 9 3 8 0}$ & 0,1364 & 0,9716 & 0,1701 & 0,9455 & 0,1105 & $\mathbf{0 , 8 8 8 6}$ & 0,2400 & $\mathbf{0 , 8 9 7 6}$ & 0,1693 & $\mathbf{0 , 9 5 2 4}$ \\
\hline & & $\mathbf{O}$ & 0,2516 & 0,9330 & 0,1145 & 0,9700 & 0,1756 & 0,9452 & 0,0997 & 0,8757 & 0,2569 & 0,8827 & 0,1787 & 0,9446 \\
\hline & & B & 0,2423 & 0,9268 & 0,1135 & 0,9717 & 0,1803 & 0,9412 & 0,0975 & 0,8855 & 0,2631 & 0,8734 & 0,1787 & 0,9442 \\
\hline & \multirow{3}{*}{$\begin{array}{c}\text { TR } \\
\text { EKKA }\end{array}$} & $\mathbf{K}$ & 0,2716 & 0,9366 & 0,1257 & 0,9654 & 0,1985 & 0,9324 & 0,1022 & 0,8495 & 0,3314 & 0,7569 & 0,2054 & 0,9253 \\
\hline & & O & 0,2377 & 0,9272 & 0,1142 & 0,9720 & 0,1737 & 0,9401 & 0,0918 & 0,8853 & 0,2427 & 0,8734 & 0,1715 & 0,9446 \\
\hline & & B & 0,2298 & 0,9306 & 0,1192 & 0,9715 & 0,1788 & 0,9433 & 0,1040 & 0,8876 & 0,2597 & 0,8819 & 0,1766 & 0,9475 \\
\hline \multirow{6}{*}{ 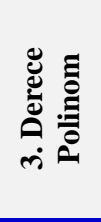 } & \multirow{3}{*}{ BR } & $\mathbf{K}$ & 0,2664 & 0,9422 & 0,1655 & 0,9573 & 0,2070 & 0,9352 & 0,1317 & 0,8720 & 0,2517 & 0,8906 & 0,2022 & 0,9439 \\
\hline & & O & 0,2869 & 0,9421 & 0,1456 & 0,9526 & 0,2089 & 0,9279 & 0,1174 & 0,8290 & 0,2353 & 0,8999 & 0,1993 & 0,9354 \\
\hline & & B & 0,3063 & 0,9365 & 0,1450 & 0,9532 & 0,2115 & 0,9283 & 0,1120 & 0,8332 & 0,2487 & 0,8916 & 0,2058 & 0,9327 \\
\hline & \multirow{3}{*}{$\begin{array}{c}\text { TR } \\
\text { EKKA }\end{array}$} & $\mathbf{K}$ & 0,3826 & 0,9317 & 0,1622 & 0,9271 & 0,2264 & 0,9185 & 0,1192 & 0,7911 & 0,2363 & 0,8910 & 0,2309 & 0,8972 \\
\hline & & O & 0,2969 & 0,9387 & 0,1381 & 0,9552 & 0,1953 & 0,9345 & 0,1145 & 0,8163 & 0,2133 & 0,9116 & 0,1931 & 0,9354 \\
\hline & & B & 0,2723 & $\mathbf{0 , 9 3 9 6}$ & $\mathbf{0 , 1 4 9 8}$ & $\mathbf{0 , 9 5 2 3}$ & 0,2163 & $\mathbf{0 , 9 2 5 3}$ & $\mathbf{0 , 1 1 4 0}$ & $\mathbf{0 , 8 4 3 8}$ & $\mathbf{0 , 2 3 6 0}$ & $\mathbf{0 , 9 0 4 3}$ & $\mathbf{0 , 1 9 8 5}$ & $\mathbf{0 , 9 3 8 7}$ \\
\hline \multirow{6}{*}{ 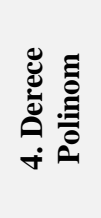 } & \multirow{3}{*}{ BR } & $\bar{K}$ & 0,2502 & 0,9432 & 0,2027 & 0,9524 & 0,2163 & $\mathbf{0 , 9 3 3 0}$ & $\mathbf{0 , 1 4 1 0}$ & $\mathbf{0 , 8 7 1 9}$ & $\mathbf{0 , 2 4 9 8}$ & $\mathbf{0 , 8 8 8 2}$ & 0,2100 & 0,9428 \\
\hline & & O & 0,2920 & 0,9344 & 0,1889 & 0,9390 & 0,2694 & 0,8980 & 0,1187 & 0,8353 & 0,2585 & 0,8873 & 0,2297 & 0,9261 \\
\hline & & B & 0,3294 & 0,9294 & 0,2022 & 0,9409 & 0,2568 & 0,9157 & 0,1337 & 0,8476 & 0,2841 & 0,8775 & 0,2417 & 0,9294 \\
\hline & \multirow{3}{*}{$\begin{array}{c}\text { TR } \\
\text { EKKA }\end{array}$} & $\mathbf{K}$ & 0,3365 & 0,9270 & 0,1711 & 0,9113 & 0,2219 & 0,9077 & 0,1292 & 0,7639 & 0,2641 & 0,8447 & 0,2246 & 0,8952 \\
\hline & & O & 0,3004 & 0,9343 & 0,1429 & 0,9540 & 0,1981 & 0,9299 & 0,1137 & 0,8304 & 0,2139 & 0,9077 & 0,1955 & 0,9351 \\
\hline & & B & 0,2899 & 0,9356 & 0,1873 & 0,9468 & 0,2580 & 0,9173 & 0,1347 & 0,8461 & 0,2664 & 0,9022 & 0,2285 & 0,9375 \\
\hline
\end{tabular}

Kalın yazı tipiyle belirtilen satır, en iyi eğitim performansı bakımından ilgili modelin test sonuçlarını göstermektedir.

K: Küçük, O: Orta, B: Büyük örneklem boyutu. 


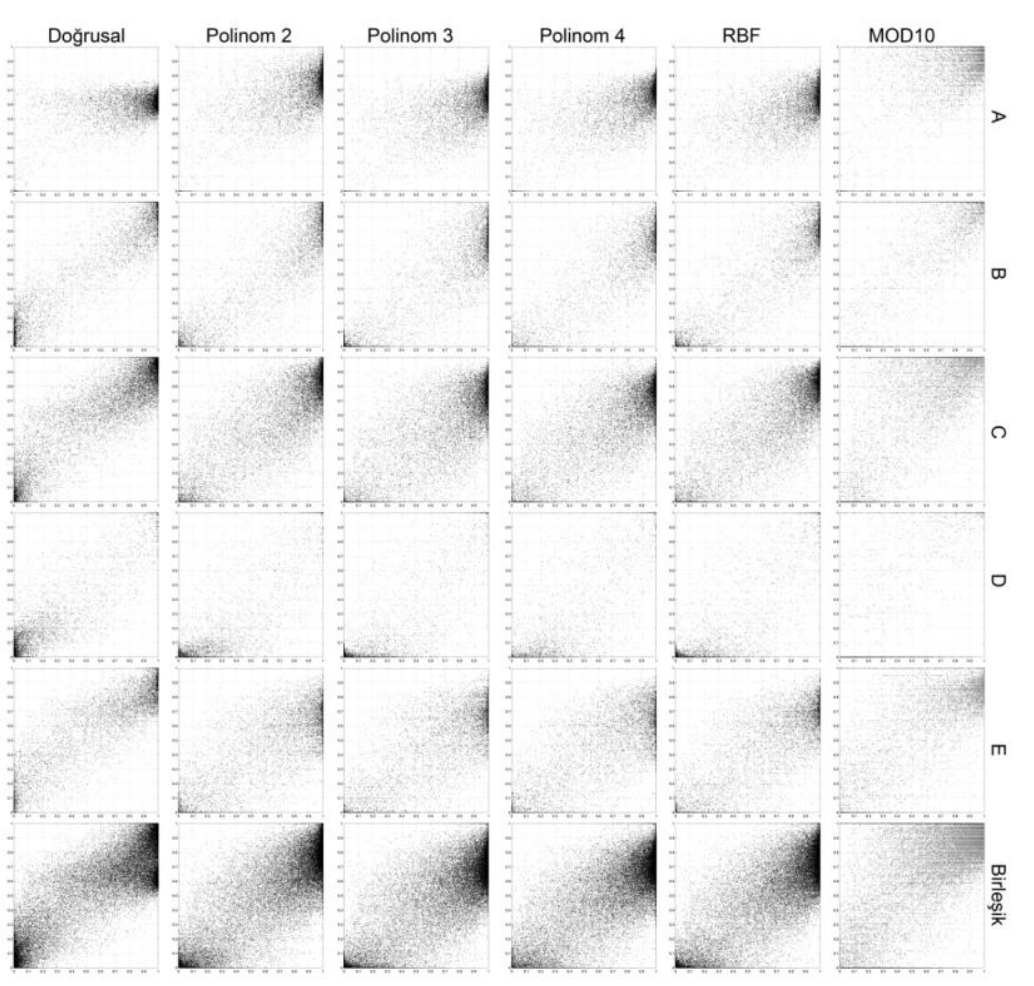

Şekil 4. Bağımsız test verisine ait EKKA değerlerinin saçılım grafikleri. Grafiklerde $x$ ekseni referans, $y$ ekseni ise modellenen EKKA değerlerine karşılık gelmektedir.

Tablo 7. DVM modellerinin eğitimi boyunca saniye bazında harcanan ortalama CPU zamanları.

\begin{tabular}{lrrr}
\hline \multirow{2}{*}{ Kernel Fonksiyonu } & \multicolumn{3}{c}{ Örneklem Boyutu } \\
\cline { 2 - 4 } & \multicolumn{1}{c}{ Küçük } & Orta & \multicolumn{1}{c}{ Büyük } \\
\hline RBF & 278,79 & 2299,50 & 8457,31 \\
Doğrusal & 10374,62 & 49335,69 & 100794,23 \\
2. Derece Polinom & 7969,15 & 46327,25 & 96512,34 \\
3. Derece Polinom & 10040,63 & 42625,48 & 106014,65 \\
4. Derece Polinom & 8905,60 & 45536,91 & 92053,59 \\
\hline
\end{tabular}

Tablo 8. DVM ve MOD10A1'den elde edilen EKKA değerleri için bağımsız test veri setlerine ait RMSE ve $R$ değerleri.

\begin{tabular}{ccccccc}
\hline \multirow{2}{*}{$\begin{array}{c}\text { Test Veri } \\
\text { Seti }\end{array}$} & \multicolumn{2}{c}{ RBF } & \multicolumn{2}{c}{ Doğrusal } & \multicolumn{2}{c}{ 2. Derece Polinom } \\
\cline { 2 - 7 } & RMSE & $\boldsymbol{R}$ & RMSE & $\boldsymbol{R}$ & RMSE & $\boldsymbol{R}$ \\
\hline $\mathbf{A}$ & 0,2825 & 0,9379 & 0,3015 & 0,9168 & 0,2046 & 0,9380 \\
$\mathbf{B}$ & 0,1212 & 0,9681 & 0,0923 & 0,9712 & 0,1364 & 0,9716 \\
$\mathbf{C}$ & 0,1785 & 0,9431 & 0,1268 & 0,9545 & 0,1701 & 0,9455 \\
$\mathbf{D}$ & 0,1077 & 0,8588 & 0,0792 & 0,9182 & 0,1105 & 0,8886 \\
E & 0,2196 & 0,9139 & 0,1425 & 0,9378 & 0,2400 & 0,8976 \\
Birleşik & 0,1825 & 0,9457 & 0,1573 & 0,9371 & 0,1693 & 0,9524 \\
\hline Test Veri & $\mathbf{3 . ~ D e r e c e ~ P o l i n o m ~}$ & $\mathbf{4 . ~ D e r e c e ~ P o l i n o m ~}$ & MOD10A1 \\
Seti & $\mathbf{R M S E}$ & $\boldsymbol{R}$ & $\mathbf{R M S E}$ & $\boldsymbol{R}$ & $\mathbf{R M S E}$ & $\boldsymbol{R}$ \\
\hline A & 0,2723 & 0,9396 & 0,2502 & 0,9432 & 0,5221 & 0,6870 \\
B & 0,1498 & 0,9523 & 0,2027 & 0,9524 & 0,2652 & 0,8461 \\
C & 0,2163 & 0,9253 & 0,2163 & 0,9330 & 0,2738 & 0,8478 \\
D & 0,1140 & 0,8438 & 0,1410 & 0,8719 & 0,1836 & 0,7089 \\
E & 0,2360 & 0,9043 & 0,2498 & 0,8882 & 0,3803 & 0,6885 \\
Birleșik & 0,1985 & 0,9387 & 0,2100 & 0,9428 & 0,3245 & 0,8270 \\
\hline
\end{tabular}


Tablo 9. RMSE ve $R$ değerleri bakımından RANOVA test sonuçlarının karşılaştırması

\begin{tabular}{|c|c|c|c|c|c|}
\hline $\mathbf{R M S E}_{i} / \boldsymbol{R}_{i}$ & $\mathbf{R M S E}_{j} / \boldsymbol{R}_{j}$ & $\begin{array}{l}\text { Ortalama Fark } \\
\text { RMSE }_{i}-\text { RMSE }_{j}\end{array}$ & $\begin{array}{c}\text { LSD testinin } \\
p \text { değeri }\end{array}$ & $\begin{array}{c}\text { Ortalama Fark } \\
R_{i}-R_{j}\end{array}$ & $\begin{array}{c}\text { LSD testinin } \\
p \text { değeri }\end{array}$ \\
\hline \multirow{5}{*}{ RBF } & Doğrusal & 0,0321 & 0,057 & $-0,0113$ & 0,370 \\
\hline & 2. Derece Polinom & 0,0102 & 0,515 & $-0,0044$ & 0,504 \\
\hline & 3. Derece Polinom & $-0,0158$ & 0,069 & 0,0106 & $0,016^{*}$ \\
\hline & 4. Derece Polinom & $-0,0297$ & 0,102 & 0,0060 & 0,347 \\
\hline & MOD10A1 & $-0,1429$ & $0,002 *$ & 0,1604 & $0,002 *$ \\
\hline \multirow{5}{*}{ Doğrusal } & RBF & $-0,0321$ & 0,057 & 0,0113 & 0,370 \\
\hline & 2. Derece Polinom & $-0,0219$ & 0,445 & 0,0070 & 0,514 \\
\hline & 3. Derece Polinom & $-0,0479$ & 0,047 & 0,0219 & 0,166 \\
\hline & 4. Derece Polinom & $-0,0617$ & 0,053 & 0,0174 & 0,209 \\
\hline & MOD10A1 & $-0,1750$ & $0,000 *$ & 0,1717 & $0,001^{*}$ \\
\hline \multirow{5}{*}{$\begin{array}{l}\text { 2. Derece } \\
\text { Polinom }\end{array}$} & RBF & $-0,0102$ & 0,515 & 0,0044 & $0,016^{*}$ \\
\hline & Doğrusal & 0,0219 & 0,445 & $-0,0070$ & 0,166 \\
\hline & 3. Derece Polinom & $-0,0260$ & 0,067 & 0,0150 & 0,102 \\
\hline & 4. Derece Polinom & $-0,0399$ & $0,003 *$ & 0,0104 & 0,466 \\
\hline & MOD10A1 & $-0,1531$ & $0,007 *$ & 0,1647 & $0,001 *$ \\
\hline \multirow{5}{*}{$\begin{array}{l}\text { 3. Derece } \\
\text { Polinom }\end{array}$} & RBF & 0,0158 & 0,069 & $-0,0106$ & $0,016^{*}$ \\
\hline & Doğrusal & 0,0479 & $0,047^{*}$ & $-0,0219$ & 0,166 \\
\hline & 2. Derece Polinom & 0,0260 & 0,067 & $-0,0150$ & 0,102 \\
\hline & 4. Derece Polinom & $-0,0399$ & 0,237 & $-0,0046$ & 0,466 \\
\hline & MOD10A1 & $-0,1531$ & $0,006^{*}$ & 0,1498 & $0,003 *$ \\
\hline \multirow{5}{*}{$\begin{array}{l}\text { 4. Derece } \\
\text { Polinom }\end{array}$} & RBF & 0,0297 & 0,102 & $-0,0060$ & 0,347 \\
\hline & Doğrusal & 0,0617 & 0,053 & $-0,0174$ & 0,209 \\
\hline & 2. Derece Polinom & 0,0399 & $0,003 *$ & $-0,0104$ & $0,031 *$ \\
\hline & 3. Derece Polinom & 0,0139 & 0,237 & 0,0046 & 0,466 \\
\hline & MOD10A1 & $-0,1133$ & $0,022 *$ & 0,1544 & $0,002 *$ \\
\hline \multirow{5}{*}{ MOD10A1 } & $\mathbf{R B F}$ & 0,1429 & $0,002 *$ & $-0,1604$ & $0,002 *$ \\
\hline & Doğrusal & 0,1750 & $0,00^{*}$ & $-0,1717$ & $0,001 *$ \\
\hline & 2. Derece Polinom & 0,1531 & $0,007 *$ & $-0,1647$ & $0,001 *$ \\
\hline & 3. Derece Polinom & 0,1271 & $0,006^{*}$ & $-0,1498$ & $0,003 *$ \\
\hline & 4. Derece Polinom & 0,1133 & $0,022 *$ & $-0,1544$ & $0,002 *$ \\
\hline
\end{tabular}

*ortalama farkın $\alpha=0,05$ önem seviyesinde istatistiksel açıdan anlamlı olduğunu göstermektedir.

\section{Sonuçlar}

Kar örtüsünün sürekli olarak izlenmesi, hem yerel hem de küresel ölçekte yeryüzünün hidrolojisi, meteorolojisi ve iklimindeki değişiklikleri izlemek açısından çok büyük öneme sahiptir. Bu çalışmada, EKKA haritalaması için parametrik olmayan DVM yönteminin uygunluğu araştırılmıştır. MODIS 1-7 bantlarına ait atmosfer üstü reflektans değerleri, NDSI, NDVI ve arazi sınıfı bağımsız değişkenler olarak kullanılırken, referans EKKA değerleri daha yüksek mekânsal çözünürlüklü Landsat 7/8 verilerinden üretilip, bağımlı değişken olarak kullanılmıştır. Bağımsız test görüntüleri üzerinde farklı model oluşturma konfigürasyonlara sahip DVM modellerinin performanslarının, MODIS'in kendi EKKA ürünü olan MOD10A1'e göre daha iyi olduğu gözlemlenmekle beraber, MOD10A1'in küresel ölçekte üretilen günlük bir ürün olduğunu vurgulamak ve bu çalışmada elde edilen sonuçların bu ürünün genel başarısını tam olarak yansıtmadığını söylemek yerinde olacaktır. DVM'lerin geleneksel istatistiksel yöntemlere göre avantajı, bir dizi bağımsız değişken ve bir bağımlı değişken arasındaki temel ilişkiyle ilgili herhangi bir önsel varsayımda bulunmamasından kaynaklanır. DVM modellerin eğitim süreci yalnızca iki parametreye bağlıdır: $i$ ) kernel fonksiyonu ve ii) $C$ 'nin seçimi.

Çalışmadan elde edilen sonuçlar ışı̆̆ında, DVM ile EKKA haritası üretmede kullanılacak en uygun kernel, CPU zamanı göz önüne alındığında, RBF kernel olarak belirlenmiştir. Modellerin eğitiminde kullanılan eğitim veri seti boyutunun oluşturulan DVM modelin performansı üzerinde her hangi bir etkisi görülmemekle birlikte, model oluşturma sürecinde kullanılan eğitim verisinin bağımlı değişkenle bağımsız değişkenler arasındaki 
ilişkiyi yüksek düzeyde temsil edebilme özelliğine sahip olması parametrik olmayan tüm makine öğrenmesi algoritmalarının başarısı için önemli bir faktör olduğunu belirtmek gerekmektedir. Bu çalışmada bulunan sonuçlara paralel olarak, literatürdeki örnekler de DVM'lerin küçük eğitim veri setleri üzerinde yüksek doğrulukla çalıştığını göstermektedir (Chi vd., 2008; Foody ve Mathur, 2004, 2006).

DVM modeller ile MODIS verilerinden EKKA haritalarının üretildiği bu çalışma, istatistiksel analiz, matematiksel modelleme ve karar verme teorisi gibi matematik bilimlerinden tekniklerin kullanılmasını içermektedir. Makine öğrenme algoritmaları ile EKKA haritalama yöntemlerinin geliştirilmesi, UA alanındaki umut verici ilerlemelerden biri olacaktır. Bu çerçeveden bakıldığında, UA'da ilk kez MODIS verilerinden EKKA haritalaması için DVM'lerin uygulanabilirliğini ve kullanımını değerlendirmesi açısından bu çalışma büyük bir katkı sağlamaktadır.

\section{Bilgilendirme}

Bu çalışma, Bora Berkay ÇİFTÇİnin Çankırı Karatekin Üniversitesi BAP biriminin OF090316L04 nolu projesince desteklenen yüksek lisans tezinden üretilmiştir.

\section{Kaynaklar}

1. Akyürek, Z., Hall D. K., Riggs, G.A., Sensoy, A. (2010). Evaluating the utility of the ANSA blended snow cover product in the mountains of eastern Turkey. International Journal of Remote Sensing, 31(14), 3727-3744.

2. Aydinozu, D., Ibret, U., Aydin, M. (2011). Analysis of Terrain Usage in Kastamonu-Ilgaz Mountain Natural Park. International Symposium on Environmental Protection and Planning: Geographic Information Systems (GIS) and Remote Sensing (RS) Applications (ISEPP), 28-29 June 2011, İzmir TURKEY.

3. Bruzzone, L., Melgani, F. (2005). Robust multiple estimator systems for the analysis of biophysical parameters from remotely sensed data. IEEE Transactions on Geoscience and Remote Sensing, 43(1), 159174.

4. Chen, J., Zhu, X., Vogelmann, J. E., Gao, F., Jin, S. (2011). A simple and effective method for filling gaps in Landsat ETM+ SLC-off images. Remote Sensing of Environment, 115(4): 1053-1064.

5. Chi, M., Feng, R., Bruzzone, L. (2008). Classification of hyperspectral remote-sensing data with primal SVM for small-sized training dataset problem. Advances in Space Research, 41(11), 1793-1799.

6. Davis CS (2002). Statistical methods for the analysis of repeated measurements: Springer Science \& Business Media.

7. Dietz, A. J., Kuenzer, C., Gessner, U., Dech, S. (2012). Remote sensing of snow - a review of available methods. International Journal of Remote Sensing, 33(13), 4094-4134.

8. Dobreva, I. D., Klein, A. G. (2011). Fractional snow cover mapping through artificial neural network analysis of MODIS surface reflectance. Remote Sensing of Environment, 115(12), 3355-3366.

9. Dodge, Y. (2008). The Concise Encyclopedia of Statistics. New York: Springer.

10. Dwyer, J., Schmidt, G. (2006). The MODIS Reprojection Tool. In J. J. Qu, W. Gao, M. Kafatos, R. E. Murphy ve V. V. Salomonson (Eds.), Earth Science Satellite Remote Sensing: Vol. 2: Data, Computational Processing, and Tools (162-177). Berlin, Heidelberg: Springer Berlin Heidelberg.

11. Fisher, W. D., Camp, T. K., Krzhizhanovskaya, V. V. (2017). Anomaly detection in earth dam and levee passive seismic data using support vector machines and automatic feature selection. Journal of Computational Science, 20, 143-153.

12. Foody, G. M., Mathur, A. (2004). Toward intelligent training of supervised image classifications: directing training data acquisition for SVM classification. Remote Sensing of Environment, 93(1-2), 107117.

13. Foody, G. M., Mathur, A. (2006). The use of small training sets containing mixed pixels for accurate hard image classification: Training on mixed spectral responses for classification by a SVM. Remote Sensing of Environment, 103(2), 179-189.

14. Frei, A., Tedesco, M., Lee, S., Foster, J., Hall, D. K., Kelly, R., Robinson, D. A. (2012). A review of global satellite-derived snow products. Advances in Space Research, 50(8), 1007-1029.

15. Friedl, M. A., Sulla-Menashe, D., Tan, B., Schneider, A., Ramankutty, N., Sibley, A., Huang, X. (2010). MODIS Collection 5 global land cover: Algorithm refinements and characterization of new datasets. Remote Sensing of Environment, 114(1), 168-182. 
16. Hall, D., Foster, J., Verbyla, D., Klein, A., Benson, C. (1998). Assessment of snow-cover mapping accuracy in a variety of vegetation-cover densities in central Alaska. Remote Sensing of Environment, 66(2), 129-137.

17. Hall, D. K., Riggs, G. A., Salomonson, V. V. (1995). Development of Methods for Mapping Global Snow Cover Using Moderate Resolution Imaging Spectroradiometer Data. Remote Sensing of Environment, 54, 127-140.

18. Hall, D. K., Riggs, G. A., Salomonson, V. V. (2006). MODIS Snow and Sea Ice Products. In J. J. Qu, W. Gao, M. Kafatos, R. E. Murphy ve V. V. Salomonson (Eds.), Earth Science Satellite Remote Sensing Vol. 1: Science and Instruments (154-181). Berlin, Heidelberg: Springer.

19. Hall, D. K., Riggs, G. A., Salomonson, V. V., DiGirolamo, N. E., Bayr, K. J. (2002). MODIS snowcover products. Remote Sensing of Environment, 83, 181-194.

20. Haykin, S. (2009). Neural Networks and Learning Machines (3rd ed.). Upper Saddle River, NJ, USA: Pearson.

21. Kaheil, Y. H., Rosero, E., Gill, M. K., McKee, M., Bastidas, L. A. (2008). Downscaling and forecasting of evapotranspiration using a synthetic model of wavelets and support vector machines. IEEE Transactions on Geoscience and Remote Sensing, 46(9), 2692-2707.

22. Kavzoglu, T., Colkesen, I. (2009). A kernel functions analysis for support vector machines for land cover classification. International Journal of Applied Earth Observation and Geoinformation, 11(5), 352-359.

23. Klein, A. G., Barnett, A. C. (2003). Validation of daily MODIS snow cover maps of the Upper Rio Grande River Basin for the 2000-2001 snow year. Remote Sensing of Environment, 86(2), 162-176.

24. Kumar, D., Meghwani, S. S., Thakur, M. (2016). Proximal support vector machine based hybrid prediction models for trend forecasting in financial markets. Journal of Computational Science, 17, 1-13.

25. Kumar, K. K., Shelokar, P. S. (2008). An SVM method using evolutionary information for the identification of allergenic proteins. Bioinformation, 2(6), 253.

26. Kuter, N. (2008). Evaluation of Ilgaz Mountain National Park in Terms of Forest Landscape and Aesthetics. Turkish Journal of Forestry, 1, 36-47.

27. Kuter, S., Akyurek, Z., Weber, G.W. (2018). Retrieval of fractional snow covered area from MODIS data by multivariate adaptive regression splines. Remote Sensing of Environment, 205, 236-252.

28. Lehning, M., Völksch, I., Gustafsson, D., Nguyen, T. A., Stähli, M., Zappa, M. (2006). ALPINE3D: a detailed model of mountain surface processes and its application to snow hydrology. Hydrological Processes, 20(10), 2111-2128.

29. Liu, Y., Chen, Y. (2007). Face Recognition Using Total Margin-Based Adaptive Fuzzy Support Vector Machines. IEEE Transactions on Neural Networks, 18(1), 178-192.

30. Luojus, K. P., Pulliainen, J. T., Metsamaki, S. J., Hallikainen, M. T. (2007). Snow-covered area estimation using satellite radar wide-swath images. IEEE Transactions on Geoscience and Remote Sensing, 45(4), 978-989.

31. Mattera, D., Haykin, S. (1999). Support vector machines for dynamic reconstruction of a chaotic system. In S. Bernhard, J. C. B. Christopher ve J. S. Alexander (Eds.), Advances in Kernel Methods - Support Vector Learning (211-241). Cambridge, MA: MIT Press.

32. Melgani, F., Bruzzone, L. (2004). Classification of hyperspectral remote sensing images with support vector machines. Geoscience and Remote Sensing, IEEE Transactions on, 42(8), 1778-1790.

33. Mountrakis, G., Im, J., Ogole, C. (2011). Support vector machines in remote sensing: A review. ISPRS Journal of Photogrammetry and Remote Sensing, 66(3), 247-259.

34. Müller, K.-R., Smola, A. J., Rätsch, G., Schölkopf, B., Kohlmorgen, J., Vapnik, V. (1997, October 810, 1997 ). Predicting time series with support vector machines. International Conference on Artificial Neural Networks - ICANN'97, Lausanne, Switzerland.

35. Painter, T. H., Rittger, K., McKenzie, C., Slaughter, P., Davis, R. E., Dozier, J. (2009). Retrieval of subpixel snow covered area, grain size, and albedo from MODIS. Remote Sensing of Environment, 113(4), 868-879.

36. Pal, M., Mather, P. M. (2005). Support vector machines for classification in remote sensing. International Journal of Remote Sensing, 26(5), 1007-1011.

37. Piazzi, G., Tanis, C. M., Kuter, S., Simsek, B., Puca, S., Toniazzo, A., Takala, M., Akyürek, Z., Gabellani, S., Arslan, A. N. (2019). Cross-Country Assessment of H-SAF Snow Products by Sentinel-2 Imagery Validated against In-Situ Observations and Webcam Photography. Geosciences, 9(3), 129.

38. Richards, J. A., Jia, X. (2006). Remote sensing digital image analysis: An introduction (4th ed.). Germany: Springer.

39. Romanov, P., Tarpley, D., Gutman, G., Carroll, T. (2003). Mapping and monitoring of the snow cover fraction over North America. Journal of Geophysical Research, Atmospheres, 108(D16). 
40. Scaramuzza, P., Micijevic, E., Chander, G. (2004). SLC-off Gap-Filled Products Gap-Fill Algorithm Methodology Phase 2 Gap-Fill Algorithm. US Geological Survey Earth Resources Observation and Science (EROS) Center.

41. Shanthi, N., Duraiswamy, K. (2010). A novel SVM-based handwritten Tamil character recognition system. Pattern Analysis and Applications, 13(2), 173-180.

42. Siljamo, N., Hyvärinen, O. (2011). New Geostationary Satellite-Based Snow-Cover Algorithm. Journal of Applied Meteorology and Climatology, 50(6), 1275-1290.

43. Smola, A. J., Schölkopf, B. (2004). A tutorial on support vector regression. Statistics and Computing, 14(3), 199-222.

44. Vapnik, V. N. (1995). The Nature of Statistical Learning Theory: Springer Heidelberg.

45. Vermote, E. F., Kotchenova, S. Y., Ray, J. P. (2011). MODIS surface reflectance user's guide - Version 1.3. MODIS Land Surface Reflectance Science Computing Facility

46. Wolfe, R. E. (2006). MODIS Geolocation. In J. J. Qu, W. Gao, M. Kafatos, R. E. Murphy ve V. V. Salomonson (Eds.), Earth Science Satellite Remote Sensing Vol. 1: Science and Instruments (50-73). Berlin, Heidelberg: Springer.

47. Xiong, X., Isaacman, A., Barnes, W. (2006). MODIS Level-1B Products. In J. J. Qu, W. Gao, M. Kafatos, R. E. Murphy ve V. V. Salomonson (Eds.), Earth Science Satellite Remote Sensing (33-49): Springer Berlin Heidelberg.

48. Yuan, F.-C., Lee, C.-H. (2015). Using least square support vector regression with genetic algorithm to forecast beta systematic risk. Journal of Computational Science, 11, 26-33.

49. Zhang, T. (2005). Influence of the seasonal snow cover on the ground thermal regime: An overview. Reviews of Geophysics, 43(4) 1-23.

50. Zheng, S., Shi, W.-z., Liu, J., Tian, J. (2008). Remote sensing image fusion using multiscale mapped LSSVM. IEEE Transactions on Geoscience and Remote Sensing, 46(5), 1313-1322. 